\title{
The effect of $\beta$-aminobutyric acid (BABA) on root knot nematode and soft rot pathogen disease complexes in Solanum tuberosum plants
}

\author{
Aobakwe Mongae and Lucy Moleleki \\ Forestry and Agricultural Biotechnology Institute \\ Department of Microbiology and Plant Pathology, University of Pretoria, Lunnon Road \\ Corresponding author \\ Tel: $+27(0) 124204662$ \\ Fax: $+27(0) 124203266$ \\ Email: lucy.moleleki@up.ac.za
}

\section{Abstract}

The efficacy of three elicitors, DL- $\beta$-aminobutyric acid (BABA), Acibenzolar-S-methyl (Bion) and Messenger (Harpin) on potato plants inoculated with Meloidogyne incognita second stage juveniles (J2s) was investigated in this study. The efficacy of each elicitor was evaluated based on galling index, egg numbers, total root knot nematode (RKN) population numbers, number of juveniles and the percentage of females in respective extracted populations per treatment at 28 and $56 \mathrm{dpi}$. There was a significant decrease in galling indices of all treated compared to untreated control plants. The highest percentage reduction was observed for $20 \mathrm{mM}$ BABA-treated plants (33\%) followed by 5mM BABA (23\%), 50mg/L Bion (18\%), 100mg/L Bion (15\%) and Messenger (8\%). The number of eggs extracted from plants treated with 20mM BABA was significantly lower (66\%) compared to untreated controls. Furthermore, treating plants with $20 \mathrm{mM}$ BABA decreased the total RKN population numbers by $55 \%$ whilst the decrease observed for 
Bion and Messenger was between 24-39\%. Of the three tested elicitors, 20mM BABA was found to be the most effective elicitor at both 28 and 56 dpi. Hence, it was selected for further testing against RKN and Pectobacterium carotovorum subsp. brasiliense $(P c b)$ disease complex. Efficacy was tested by comparing the colony forming units (cfu) of $P c b$ from treated and untreated control plants inoculated with $M$. incongita and $P c b$ simultaneously. The concentration of $P c b$ from untreated plants inoculated with both pathogens was significantly higher $\left(3.3 \times 10^{3} \mathrm{cfu} / \mathrm{ml}\right)$ compared to their treated counterparts $\left(8.71 \times 10^{2} \mathrm{cfu} / \mathrm{ml}\right)$. This suggests that BABA has the potential to decrease soft rot bacterial infections in RKN disease complexes by decreasing the rate of RKN infection. This is the first report where BABA is shown to decrease the infection rate of RKN as a primary causal agent in combination with a secondary pathogen.

KEYWORDS: root knot nematode (RKN); soft rot enterobacteriaceae (SRE); elicitor; $\beta$ aminobutyric acid (BABA)

\section{Introduction}

Root knot nematodes (RKN) and Soft Rot Enterobacteriaceae (SRE) are important pathogens of potatoes in South Africa (Moleleki et al., 2013; Onkendi and Moleleki, 2013a; Onkendi et al., 2014). A recent survey of RKN infecting potatoes in South Africa, identified several different Meloidogyne species including the highly aggressive $M$. enterolobii (Onkendi and Moleleki 2013 a and b). This is of major concern, particularly in view of the fact that Temik (Aldicarb) one of the main nematicides growers use against RKN, has recently been banned for use in potatoes in South Africa. Limited chemical nematicide options could lead to very high plant parasitic nematode populations in the rhizosphere. As populations increase, we can anticipate an increase in disease 
complexes by RKN with other pathogens. Such disease complexes have been demonstrated between RKN and fungal, bacterial as well as virus soil-borne phytopathogens (Sidiqqui et al., 2010). In most instances, these interactions between RKN and secondary pathogens leads to an increase in the severity of disease caused by the secondary pathogen (Alam et al., 1990; Chindo et al. 1991; Walker et al., 1998; Udo et al., 2003). In a recent study, we demonstrated possible interactions between Pectobacterium and Meloidogyne spp second stage juveniles (J2s) (Mongae et al. 2013). In that study, we showed that $P c b$ cells attach to $M$. incognita J2s and this could potentially lead to dissemination of Pectobacterium spp in the soil. We also showed that $P c b$ takes advantages of Meloidogyne $\mathrm{J} 2$-induced wounds to penetrate intact potato tubers. The combined effect of the primary (RKN) and secondary (SRE) pathogens is of major concern due to potential yield losses. For this reason, it is important to investigate alternative management strategies that target both primary and secondary pathogens rather than single pathogens.

There is currently an urgent need to consider alternative environmentally friendly management strategies for the control of root knot nematodes and associated secondary pathogens. Consequently, induced resistance using elicitors, has become an attractive method of plant disease management (Vallad and Goodman 2004; Conrath et al., 2006). Induced resistance can be attained by using chemical analogues of salicylic acid (such as 2,6 dichlroisonicotinic acid [INA], DL- $\beta$-aminobutyric acid (BABA) and benzothiadiazole-S-methyl ester [Bion]) for Systemic Acquired Resistance (SAR) or jasmonic acid (e.g. Methyl jasmonate [Mj]) for Induced Systemic Resistance (ISR) (Hamiduzzaman et. al 2005; El-Gamal et. al 2007). Induced resistance has also been demonstrated through the use Messenger ${ }^{\mathrm{TM}}$ (Harpin), a naturally occurring protein derived from the causal agent of fire blight (Erwinia amylovora). 
Elicitor induced resistance has not been widely explored for control of RKN although there are several reports (Oka et al., 1999; Oka and Cohen 2001; Nandi et al., 2003; Channasri et al., 2006; Vieira dos Santos et al., 2013). However, there are hardly any studies investigating the effect of elicitors against RKN as a primary pathogen in conjunction with a secondary pathogen.

The aim of this study was to determine the efficacy of chemical resistance inducers, DL- $\beta$-aminobutyric acid (BABA), Acibenzolar-s-methyl (Bion) and Messenger (Harpin) against a) RKN infection and b) RKN-SRE disease complex on potato plants.

\section{Materials and Methods}

Meloidogyne incognita population

Single isolates of Meloidogyne incognita were maintained on root knot nematode susceptible tomato plants (cv Rodade) in the glass house at $26^{\circ} \mathrm{C}$. To obtain $M$. incognita second stage juveniles (J2s) for inoculations, egg masses were harvested from root knots using a pair of tweezers and a blade. To allow hatching, eggs were placed on a $25 \mu \mathrm{M}$ sieve in a plastic container and covered with water at room temperature for approximately $72 \mathrm{~h}$.

Media and culture conditions for Pectobacterium carotovorum subsp brasiliense

A glycerol stock of Pectobacterium carotovorum subsp brasiliense $(P c b)$ transformed with a plasmid (pMP7604) harbouring the red fluorescent protein (mCherry) and tetracycline resistance genes was retrieved from the $-70^{\circ} \mathrm{C}$ freezer (Lagendijk et al., 
2010; Mongae et al., 2013). Single colonies of $P c b$ mCherry were prepared from stocks by streaking on nutrient agar supplemented with $12.5 \mu \mathrm{g} / \mathrm{ml}$ tetracycline then incubated for two days at $37^{\circ} \mathrm{C}$. Thereafter, a single colony of Pcb_mCherry was inoculated into $10 \mathrm{ml}$ Luria Berthani (LB) broth at $37^{\circ} \mathrm{C}$ for $16 \mathrm{~h}$ in a shaking incubator at $150 \mathrm{rpm}$. Bacteria suspensions were pelleted by centrifugation for $5 \mathrm{~min}$ at $5000 \mathrm{rpm}$. Pelleted overnight cultures were washed three times followed by resuspension in $10 \mathrm{mM} \mathrm{MgSO}$. Resuspended bacteria cells were adjusted to an $\mathrm{OD}_{600}=0.1$ (equivalent to $10^{8} \mathrm{cfu} / \mathrm{ml}$ ).

Inhibition assays

A 100 freshly hatched $M$. incognita J2s were co-incubated with three elicitors at the following concentrations a) BABA (5 mM and $20 \mathrm{mM}$ ) b) Bion (50 mg/L and $100 \mathrm{mg} / \mathrm{L}$ ) c) Harpin $(0.4 \mathrm{~g} / \mathrm{L})$ and water in a $50 \mathrm{ml}$ solution each for five days at room temperature. Thereafter, the percentage of mobile vs immobile J2s in each elicitor solution and water control was determined based on mobility and agility. This was done by decanting the nematode suspension in each solution onto a MacMaster slide and counting the number of immobile J2s under the stereo microscope (Olympus SZX10).

Elicitor treatments and nematode inoculations

Five week old Solanum tuberosum cv Mondial plants in pots in the glasshouse were treated by soil-drench with $100 \mathrm{ml}$ of $5 \mathrm{mM}$ or $20 \mathrm{mM} \mathrm{BABA}, 50 \mathrm{mg} / \mathrm{L}$ or $100 \mathrm{mg} / \mathrm{L}$ Bion three days prior inoculation. On the other hand, Messenger was applied on seed 
tubers by immersion in $0.4 \mathrm{~g} / \mathrm{L}$ Messenger solution for $3 \mathrm{~min}$ followed by drying at $26^{\circ} \mathrm{C}$ for 24 hours. Thereafter, the seed tubers were planted and maintained in the glasshouse at $26^{\circ} \mathrm{C}$ for five weeks. During these five weeks, Messenger was continuously applied by spraying potato plant leaves at 14 day intervals. All elicitortreated plants were drench-inoculated with 500 freshly hatched $M$. incognita J2s per plant. Each experiment consisted of 18 plants per treatment with three independent biological replicates. Trials were conducted for a period of 56 days post inoculation (dpi) and roots were harvested at two time points, $28 \mathrm{dpi}$ and $56 \mathrm{dpi}$. At each of these time points, roots of nine plants per treatment were harvested and the efficacy of the various elicitors against RKN infection was evaluated using the following parameters: galling index (Gl), egg numbers (EN), total RKN population numbers (NP), the number of J2s and the percentage of females (FP) in the total RKN populations per treatment compared to untreated control plants.

Assessment of nematode reproductivity

Galling Index

Roots of treated and control plants harvested at 28 and 56 dpi were washed and galling indices were measured using a scale provided by Taylor and Sasser (1978): $0=$ (no galling); $1=1-2$ galls (slight galling); $2=3-10$ galls (mild galling); $3=11-30$ galls (moderate galling); $4=31$ - 100 (heavy galling); $5=>100$ galls (extreme galling). 
Egg numbers

To determine the average number of eggs per treatment, roots of nine plants sampled per treatment per time point were pooled and $20 \mathrm{~g}$ of the combined root mass was used. The average presented is of three independent experiments. Eggs were extracted by suspending roots in $300 \mathrm{ml} 3.0 \%$ sodium hypochlorite in $500 \mathrm{ml}$ Shcott bottles followed by vigorous shaking (Hussey and Barker 1973). Thereafter, eggs were collected on $20 \mu \mathrm{M}$ sieve, resuspended in $50 \mathrm{ml}$ sterile water and counted using a McMaster counting slide under a stereo microscope (Olympus SZX10).

Root Knot Nematode populations

To calculate the total RKN population (NP), $20 \mathrm{~g}$ combined roots of nine plants (three indpendent replicates) were cut into small pieces, washed and isolated according to methods previously published elsewhere (Onkendi and Moleleki 2013b). Briefly pieces of roots were transferred into a domestic blender with $100 \mathrm{~mL}$ of $1 \%(\mathrm{v} / \mathrm{v})$ bleach and distilled water to reach a final volume of $250 \mathrm{ml}$, before being macerated for $35 \mathrm{~s}$. The suspension consisting of root-knot nematodes and potato debri was decanted on a set of nested sieves with decreasing mesh size of $710,150,45$ and $38 \mu \mathrm{m}$. The residue was collected on the $38 \mu \mathrm{m}$-mesh sieve transferred into a beaker and 1 teaspoon of kaolin was added, stirred well and centrifuged in $50 \mathrm{~mL}$ Falcon tubes at 3500 r.p.m for 7 min. The supernatant was then discarded gently and sucrose solution (at $450 \mathrm{~g} / \mathrm{l}$ ) added to the Falcon tubes before centrifuging at 3500 r.p.m for 3 min. Finally, the supernatant was decanted into a $38 \mathrm{Im}$-mesh sieve, rinsed well with tap water to remove the sucrose 
solution, and $50 \mathrm{~mL}$ of the residue collected in a sample bottle for examination and counting of the nematodes under a stereomicroscope.

RKN and SRE combined inoculation

The effect of 20mM BABA against RKN-SRE disease complex on potato was evaluated as follows: Five week old $S$. tuberosum cv. Mondial pot plants were treated with $100 \mathrm{ml}$ of $20 \mathrm{mM}$ BABA solution by soil-drench three days prior inoculation. Thereafter, plants were simultaneously soil-drench inoculated with freshly hatched 500 M. incognita J2s and $50 \mathrm{ml}$ overnight cultures of $P c b$ mCherry $\left(1 \times 10^{8} \mathrm{cfu} / \mathrm{ml}\right)$, or with $1 \times 10^{8} \mathrm{cfu} / \mathrm{ml}$ Pcb_mCherry or $500 \mathrm{M}$. incognita J2s alone. As negative controls, untreated plants were inoculated with $P c b$ m $\mathrm{mCherry}$ and $M$. incognita simultaneously or with either Pcb_ mCherry or $M$. incognita alone. Plants were maintained for a period of $28 \mathrm{dpi}$, thereafter the effect of BABA on RKN as well as on RKN-SRE disease complex was evaluated. The effect of $20 \mathrm{mM}$ on RKN-SRE was evaluated by enumerating Pcb_mCherry colony forming units (CFU) per treatment. Average CFU was calculated by first grinding $20 \mathrm{~g}$ combined surface sterilised roots and mother tuber tissue followed by serial dilutions and plating on nutrient agar supplemented with $12.5 \mu \mathrm{g} \cdot \mathrm{ml}^{-1}$ of tetracycline. Plates were incubated for 48 hours at $28^{\circ} \mathrm{C}$, colonies were counted and the average CFU of Pcb_mCherry in the roots and mother tuber combination in each treatment was calculated. Three independent trials were conducted and 10 plants were used per treatment to calculate the average CFU in each trial. Each experiment was repeated three times. 
Statistical analysis

All experiments were conducted in triplicates. Where appropriate, means of the three experiments are presented and statistical significance was analysed by $T$-Test or ANOVA (JMP v5).

\section{Results}

Biocidal effect of elicitors on root knot nematodes

Prior to testing their efficacy, the three selected elicitors were first evaluated for potential biocidal effect against RKN at the following concentrations a) BABA (5mM and $20 \mathrm{mM}) \mathrm{b}$ ) Bion $(50 \mathrm{mg} / \mathrm{L}$ and $100 \mathrm{mg} / \mathrm{L})$ and $\mathrm{c}$ ) Harpin $(0.4 \mathrm{~g} / \mathrm{L})$. To this end, 100 freshly hatched $M$. incognita second stage juveniles (J2s) were suspended in $50 \mathrm{ml}$ solution of each of the inducers at the different concentrations. After five days incubation at $25^{\circ} \mathrm{C}$, the number of mobile compared to immobile J2s was evaluated. The percentage of immobile J2s in the different treatments ranged between 10.4 and $11.7 \%$. This was comparable to the water control which had $10.3 \%$ immobile J2s. These results therefore indicated that the different elicitors, at the tested concentrations, do not have any direct biocidal effects on $M$. incognita J2s. This, therefore, eliminates the possibility that these chemicals could have a direct effect on the J2s in the soil outside plant tissue. Hence, any observed effects of the elicitors could therefore be attributed to increased plant defences rather than direct toxicity on nematodes. 
The effect of three elicitors on RKN reproduction i potato plants

To test the efficacy of the different elicitors, roots of treated and control plants were harvested at $56 \mathrm{dpi}$, washed and galling indices were measured using a scale provided by Taylor and Sasser (1978): $0=$ (no galling); $1=1-2$ galls (slight galling) $; 2=$ 3 - 10 galls (mild galling); $3=11$ - 30 galls (moderate galling); $4=31-100$ (heavy galling); $5=>100$ galls (extreme galling). An average galling index for each treatment in the three independent trials is presented on Table $1 \mathrm{Gl}$. As expected, untreated but RKN-inoculated plants had the highest galling index of 3.9. Messenger showed a slight reduction with a galling index of 3.6 followed by the two Bion treated plants which had galling indices of 3.2 and 3.3 (Table $1 \mathrm{Gl}$ ). The least galling was observed for plants treated with $5 \mathrm{mM}$ and $20 \mathrm{mM}$ BABA with galling indices of 3 and 2.6, respectively. The overall percentage decrease in galling indices of the different treatments compared to untreated controls was as follows; the highest percentage decrease in galling was observed for 20mM BABA treated plants (33\%), followed by $5 \mathrm{mM}$ BABA $(23 \%), 50 \mathrm{mg} / \mathrm{L}$ Bion (18\%), 100mg/L Bion (15\%) and Messenger (8\%). These results provided an early indication that 20mM BABA was the most effective of the three tested elicitors. However, further confirmation was sought by analyzing other parameters such as number of eggs and total RKN population.

The highest average number of eggs (10464) was extracted from untreated control plants followed by Messenger and Bion (Table 1 EN). A significantly lower average number of eggs (3552 and 5664) was extracted from plants treated with $20 \mathrm{mM}$ and $5 \mathrm{mM}$ BABA, respectively. This represented a percentage reduction of 66 and $45 \%$ in the two BABA treatments compared to controls. 
Table 1: Galling index, number of eggs, nematode population, second stage juvenile and female population obtained per 20 gram roots of potato (Solunum tuberosum cv Mondial) 56 dpi with Bion ( 50 and $100 \mathrm{mg} / \mathrm{L}$ ), BABA ( 5 and $20 \mathrm{mM}$ ) and Messenger $(0.4 \mathrm{~g} / \mathrm{L})$ at different concentrations. Significant differences were calculated based on three independent pot experiments using the Student-t test (0.05\% confidence interval) and these are inferred by the use of different letters next to values within one column.

\begin{tabular}{|l|l|l|l|l|l|}
\hline Treatments & $\mathbf{G l}^{\mathrm{a}}$ & $\mathbf{E N}^{\mathrm{b}}$ & $\mathbf{N P}^{\mathbf{c}}$ & $\mathbf{J 2 s}^{\mathrm{d}}$ & $\mathbf{F P}^{\mathbf{e}}$ \\
\hline 5mM BABA & $3 \mathrm{c}$ & $5664 \mathrm{c}$ & $50.5 \mathrm{a}$ & $12.5 \mathrm{c}$ & $74.5 \mathrm{ab}$ \\
\hline $\mathbf{2 0 m M ~ B A B A}$ & $2.6 \mathrm{~d}$ & $3552 \mathrm{~d}$ & $37.6 \mathrm{c}$ & $7.6 \mathrm{~d}$ & $79.4 \mathrm{a}$ \\
\hline $\mathbf{5 0 \mathbf { m g }}$ /L Bion & $3.2 \mathrm{bc}$ & $7488 \mathrm{~b}$ & $60.2 \mathrm{~b}$ & $18.3 \mathrm{~b}$ & $69.8 \mathrm{bc}$ \\
\hline $\mathbf{1 0 0 \mathbf { m g }}$ /L Bion & $3.3 \mathrm{bc}$ & $8448 \mathrm{~b}$ & $50.0 \mathrm{a}$ & $16.7 \mathrm{~b}$ & $70.2 \mathrm{bc}$ \\
\hline Messenger & $3.6 \mathrm{ab}$ & $8256 \mathrm{~b}$ & $52.7 \mathrm{a}$ & $16.6 \mathrm{~b}$ & $68.0 \mathrm{c}$ \\
\hline Untreated & $3.9 \mathrm{a}$ & $10464 \mathrm{a}$ & $82.2 \mathrm{~d}$ & $22.4 \mathrm{a}$ & $78.3 \mathrm{ab}$ \\
\hline
\end{tabular}

${ }^{\mathrm{a}} \mathrm{GI}$ - average galling index.

${ }^{\mathrm{b}} \mathrm{EN}$ - average egg numbers.

${ }^{\mathrm{N}} \mathrm{NP}-\mathrm{M}$. incognita populations.

dJ2s - average number of J2s in M. incognita populations.

${ }^{\mathrm{e}} \mathrm{FP}$ - average percentage of females in $M$. incognita population.

From extracted total RKN population, the number of juveniles and the percentage of females was determined based on body size and shape. The highest average total RKN numbers was extracted from untreated plants (82.2) followed by $50 \mathrm{mg} / \mathrm{l}$ Bion treatments (60.2). No significant difference was observed between plants treated with $100 \mathrm{mg} / \mathrm{l} \mathrm{Bion}, 5 \mathrm{mM}$ BABA and Messenger. Of all the treatments, the lowest total number of RKN was obtained from plants treated with 20mM BABA (37.6) (Table 1 NP). Hence, in comparison to untreated controls, 20mM BABA decreased the total RKN population numbers by $55 \%$ whilst Bion and Messenger decrease ranged between 24- 
$39 \%$. When the number of $\mathrm{J} 2 \mathrm{~s}$ and the percentage of females in each population per treatment were calculated, the lowest number of J2s was observed in plants treated with $20 \mathrm{mM}$ BABA, but on the contrary, we observed a higher average percentage of females extracted from plants treated with $20 \mathrm{mM}$ BABA compared to all the other treatments.

Effect of BABA on Pcb infections as a secondary pathogen to RKN

Of the two BABA concentrations evaluated, we found that the most effective treatment overall was $20 \mathrm{mM}$ BABA. Consequently, 20mM BABA was selected to test for efficacy against combined RKN and SRE pathogens over a period of $28 \mathrm{dpi}$. To do this, we firstly evaluated the efficacy of $20 \mathrm{mM} \mathrm{BABA}$ treatment on potato plants followed by inoculation with RKN compared to untreated RKN-inoculated plants for a period of 28 dpi. Similar to our earlier observations (56 dpi), we noted that treating plants with 20 $\mathrm{mM}$ BABA prior to RKN also led to a significant reduction in galling index within this shorter period of $28 \mathrm{dpi}$ (galling index was reduced from 3.8 in control plants to 2.4 in the case of $20 \mathrm{mM}$ BABA-treated plants). Furthermore, treating potato plants with 20 mM BABA prior to inoculation with RKN reduced the number of eggs by nearly three fold (from 9216 to 2688). As shown in Figure 1, there was also a significant reduction in nematode populations and second stage juveniles isolated from BABA-treated compared to untreated control plants. Next, we sought to determine the effect of $20 \mathrm{mM}$ BABA on RKN-SRE disease complex. To do this, three independent trials were conducted and in each trial, we enumerated $P c b$ CFU/g and an average log CFU/g is 


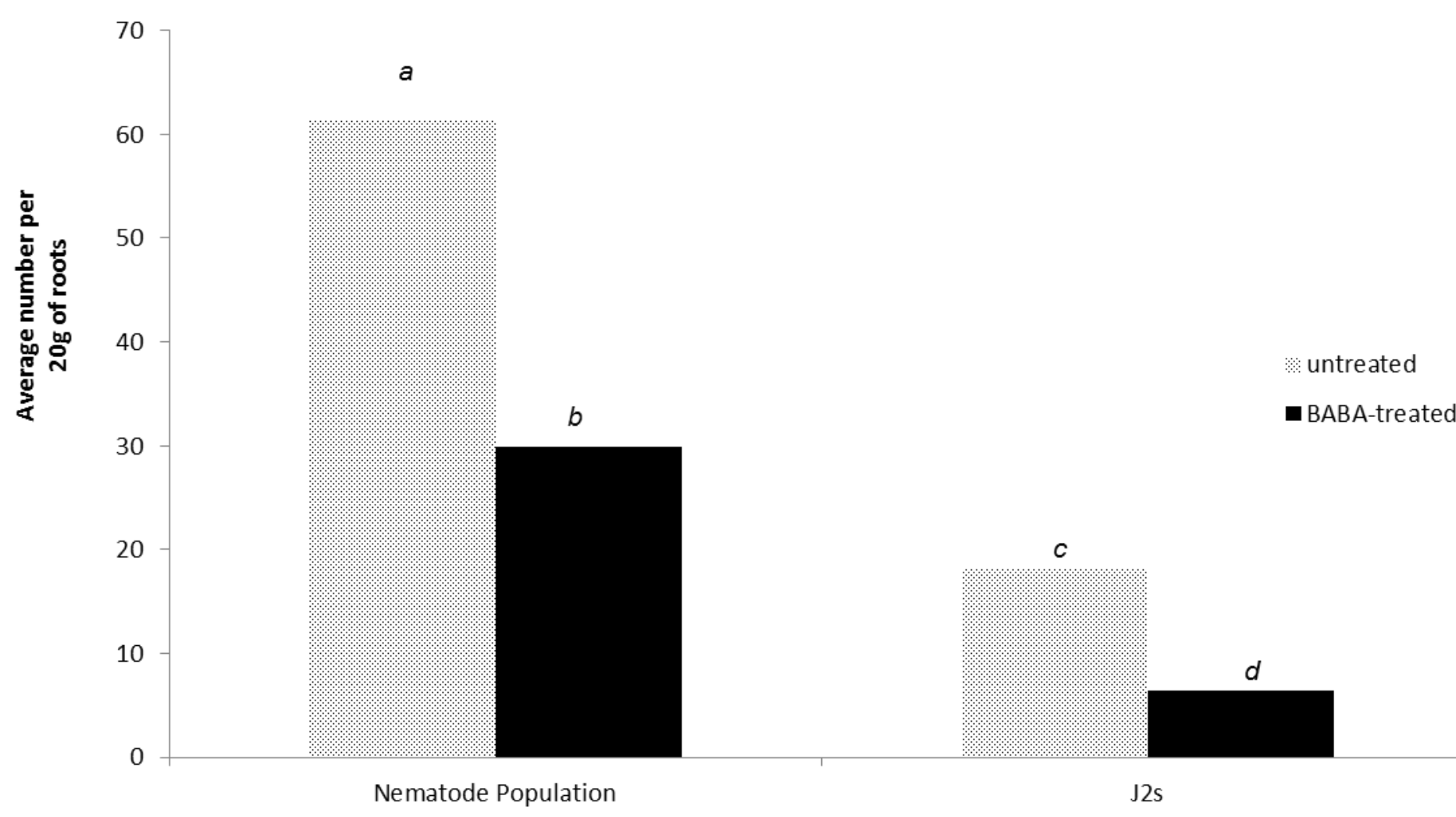

Figure 1: Total nematode population and numbers of second stage juveniles isolated from 20 roots of 20 mMBABA-treated vs control potato plants (Solanum tuberosum cv Mondial) at $28 \mathrm{dpi}$.

presented (Fig 1). As expected, no Pcb-mCherry was isolated from the controls (BABAtreated or untreated $M$. incognita inoculated plants) indicating that there was no Pcb_mCherry contamination in the soil (Fig 2). Trace amounts of Pcb_mCherry were isolated from roots of both treated and untreated plants inoculated with Pcb_mCherry (Fig 2). This confirmed our previous observations that $P c b$ has a limited ability to infect intact potato plant roots and tubers (Mongae et al., 2013; Kubheka et al., 2013). Furthermore, our results indicated that treating plants with BABA does not have a direct effect on $P c b$ as no significant difference was observed between treated and untreated 
plants inoculated with $P c b$ (Fig 2). A significant reduction was however observed in the amount of $P c b$ mCherry isolated from roots of treated plants inoculated with both $M$. incognita J2s and Pcb_mCherry compared to untreated plants inoculated with $M$. incognita J2s and Pcb_mCherry (Fig 2).

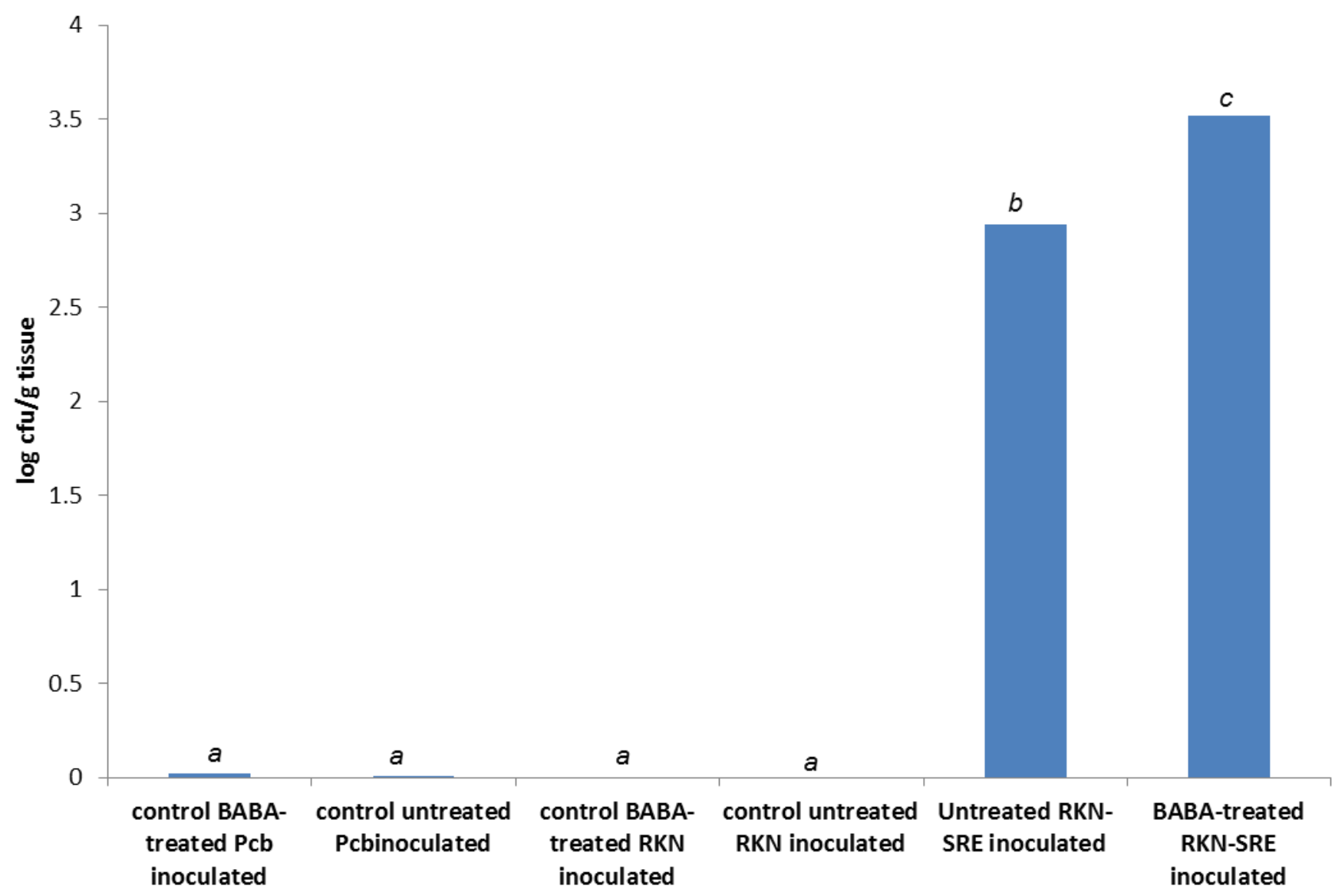

Figure 2: Pectobacterium carotovorum subsp. Brasiliense (Pcb_mCherry) isolated from roots of potato plants co-infected in RKN-Pcb. The average log CFU/g Pcb_mCherry was calculated from roots of 10 plants and the experiment was repeated three times. Bars indicate average log colony forming units of $P c b$ mCherry per gram of tissue enumerated from BABA-treated plants vs untreated plants that were inoculated with either Pcb_mCherry or $M$. incognita alone or $M$. incognita co-inoculated with $P c b \_m C h e r r y$. Different letters indicate significant differences $(p>0.05)$ 


\section{Discussion}

The withdrawal of many nematicides has heightened the threat of RKN on crop production, hence there is a dire need to investigate alternative root knot nematode management strategies. The potential use of elicitors to induce resistance against various RKN species is being widely investigated (Oka et al., 1999; Nandi et al., 2003; Chinnasri et al., 2006; Viera dos Santos et al., 2013). In this study, we investigated the effect of three elicitors BABA (5 and $20 \mathrm{mM}$ ), Bion (50 and 100mg/l) and Messenger $0.4 \mathrm{~g} / \mathrm{l}$ against RKN reproduction in potato plants. All three elicitors were all applied by drench inoculation into the soil three days prior to inoculation with RKN. Our results demonstrated that the three elicitors reduced RKN egg numbers and subsequently reducing total RKN populations. Since we observed no direct biocidal effect on RKN by each of the elicitors, it can be speculated that the elicitors either enhanced plant defence responses to RKN or reduced reproductivity of RKN in planta. However, future work is required to better understand the mode of action of each of these elicitors.

Overall, based on our pot plant experiments, the efficacy of the tested elicitors can thus be ranked, from most effective to least, as follows; BABA, Bion and Harpin. Of the two BABA concentrations evaluated, we found that the most effective treatment overall was $20 \mathrm{mM} B A B A$. It is interesting to note that several studies have noted that 20 $\mathrm{mM}$ (not less or more) is the most effective concentration of BABA to induce resistance against a wide variety of pathogens including Penicillium digitatum, Phytophthora infestans and root knot nematode (Porat et al., 2003; Oka et al., 1999 Cohen et al., 2001). In general we noted lower egg numbers, especially in BABA as well as other elicitor-treated plants compared to untreated plants. Similar observations were made by, 
by Oka et al (1999) and Chinnasri et al (2006). These authors demonstrated that lower egg populations are linked to low infection rates of BABA-treated plants compared to untreated controls. The high percentages of females isolated from BABA (and other elicitor-treated plants) indicates that even though treating plants with elicitors decreases the reproduction rate of RKN on roots, it does not inhibit subsequent developmental stages. This result is contrary to Oka and Cohen (2001) who noted a decrease in the rate of development of RKN in BABA-treated plants. However, contradictory observations regarding the effects of various plant elicitors on RKN in different crops and experimental conditions have been reported (Nandi et al., 2003; Chinnasri et al., 2006; Vieira dos Santos et al., 2013).

In a previous study, we demonstrated that an increasing number of RKN in the soil influences the number of bacteria that gain entry into potato tubers and roots in the soil (Mongae et al., 2013). Consequently, we chose to investigate the effect of $20 \mathrm{mM}$ BABA (as the most effective of the three tested elicitors) against the combined effect of RKN and SRE pathogens. We observed lower CFU of Pcb in BABA-treated compared to untreated plants where Pcb was co-inoculated with RKN. Based on our observations, we suggest that the reduction of $P c b$ CFU in the roots could be a direct consequence of reduced RKN J2 infection rate subsequently leading to reduced number of RKNgenerated-wounds. This would in turn have led to a reduction in entry sites for $P c b$. Thus it would seem that treatment of plants with $20 \mathrm{mM}$ BABA, reduced the rate of RKN $\mathrm{J} 2$ infection and this in turn led to reduced amounts of $P c b$ mCherry entering host root tissue. There is sufficient evidence showing that BABA is a broad spectrum elicitor affecting phytobacteria such as Ralstonia solaneacerum, fungi such as Phytophthora 
infestans, viruses such as the tobacco mosaic virus (TMV) and RKN such as $M$. incognita and M. chitwoodi (Ge et al., 1999; Nandi et al., 2003; Altamiranda et al., 2008; Olivieri et al., 2009; dos Santos et al., 2013; Moahmed et al., 2013). However, there are hardly any studies investigating the effect of BABA against complexes of these phytopathogens. The growing importance of RKN in crop production and their potential interaction and/or synergies with other soilborne pathogens warrants the need for an approach that addresses such complexes. Our results demonstrate the potential for BABA to be used in the management of RKN together with other soilborne pathogens with which it forms synergies.

In conclusion, this study provides evidence of reduced RKN M. incognita infection of potato roots using three different elicitors. The most effective of the three elicitors tested was BABA at a concentration of $20 \mathrm{mM}$. Furthermore, we have shown that reduced RKN infection of $20 \mathrm{mM}$ BABA leads to reduced infection of a secondary pathogen, in this case the soft rot pathogen of potatoes $(P c b)$. This is the first report where elicitors were shown to reduce infection of RKN as a primary pathogen in combination with a secondary pathogen.

Acknowledgements This study was funded by the National Research Foundation, South Africa. AM received NRF Innovative and Potatoes South Africa Development Fund bursaries. 


\section{References}

Alam, M. M., Samad, A. and Anver, S. 1990. Interaction between tomato mosaic virus and Meloidogyne incognita in tomato. Nematology mediterranean. 18, 131-133

Altamarinda E.G.C., Andreu A.B., Daleo, C.R. and Olivieri F.P. (2008) The effect of $\beta$ aminobutyric acid (BABA) on protection against Phytophthora infestans throughout the potato crop cycle. Australasian Journal of Plant Pathology 37, 421-427

Chindo, P.S., Khan, F. A. and Erinle, I.D. 1991. Reaction of three tomato cultivars to two vascular diseases in presence of the root-knot nematode, Meloidogyne incognita race 1. Crop Protection 10, 62-64

Chinnasri, B., Sipes, B. S. and Schmitt, D. P. 2006. Effects of inducers of systemic acquired resistance on reproduction of Meloidogyne javanica and Rotylenchulus reniformis in pineapple. Journal of Nematology 38(3), 319-325

Cohen Y. (2001) The BABA story of induced resistance. Phytoparasitica 29,375 - 378

Conrath, U., Beckers, G. J. M., Flors, V., García-Agustín, P., Jakab, G., Mauch, F., Newman, M., Pieterse, C. M. J., Poinssot, B., Pozo, M. J., Pugin, A., Schaffrath, U., Ton, J., Wendehenne, D., Zimmerli, L. and Mauch-Mani, B. 2006. Priming: getting ready for battle. Molecular Plant-Microbe Interactions 19(10), 1062-1071

El-Gamal, N. G., Abd-El-Kareem, F., Fotouh, Y. O. and El-Mougy, S. 2007. Induction of systemic resistance in potato plants against late and early blight diseases using chemical inducers under greenhouse and field conditions. Research Journal of Agriculture and Biological Sciences 3(2), 73-81

Ge, S., Cheng, X., Xue, Z., Yang, L. and Zheng, X. (2005). B-Aminobutyric acidmediated enhancement of resistance in tobacco against TMV and consideration of its capacity in wounded tobacco plants. Indian Journal of Biochemistry and Biophysics. $42,166-172$

Hamiduzzaman, M. M., Jakab, G., Barnavon, L., Neuhaus, J. and Mauch-Mani, B. 2005. $\beta$-Aminobutyric acid-Induced resistance against downy mildew in grapevine acts through the potentiation of callose formation and jasmonic acid signaling. Molecular Plant-Microbe Interactions 18(8), 819-829

Hussey R.S. and Barker, R.S. (1973) A comparison of collecting inocula of Meloidogyne spp., including a new technique. Plant Disease Reporter 57:1025 - 1028

Kubheka, G.C., Coutinho, T., Moleleki, N. and Moleleki, L.N. (2013) Colonisation patterns of a mCherry-tagged Pectobacterium carotovorum subsp. brasiliense in potato. Phytopathology 103(12), 1269 - 1279 
Lagendijk, E.L., Validov, S., Lamers, G.E., de Weert, S. and Bloemberg, G.V. 2010. Genetic tools for tagging Gram negative bacteria with mCherry for visualization in vitro and in natural habitats, biofilm and pathogenicity studies. FEMS Microbiology Letters 305(1), 81-90

Moahmed A.E., Hassan, K.A.M. and Abo-Elyousr (2013) Activation of tomato plant defence responses against bacterial wilt caused by Ralstonia solanacearum using DL3-aminobutyric aicd (BABA). European Journal of Plant Pathology 136, 145-157

Moleleki, L. N., Onkendi, E. M., Mongae, A. and Kubheka, G. C. 2013. Characterisation of Pectobacterium wasabiae causing blackleg and soft rot diseases in South Africa. European Journal of Plant Pathology 135, 279-288

Mongae, A., Kubheka, G.C. and Moleleki, L.N. 2013. The use of fluorescent reporter protein tagging to study the interaction between root knot nematodes and soft rot Enterobacteriaceae. Letters in Applied Microbiology 56(4), 258-263

Nandi, B., Kundu, K., Banerjee, N. and Babu, S. P. S. 2003. Salicylic acid induced suppression of Meloidogyne incognita infestation of okra and cowpea. Nematology 5, 747-752

Oka, Y. and Cohen, Y. 2001. Induced resistance to cyst and root-knot nematodes in cereals by DL- $\beta$-aminobutyric acid. European Journal of Plant Pathology 107, 219-227

Oka, Y., Cohen, Y., and Spiegel, Y. 1999. Local and systemic induced resistance to the root-knot nematode in tomato by DL- $\beta$-amino-n-butyric acid. Phytopathology 89, 11381143

Olivieri, F.P., Lobato, M.C., Altamiranda, E.G., Daleo, G.R., Huarte, M., Guevara, M.G. and Andreu, A.B., (2009) BABA effects on the behaviour of potato cultivars infected by Phytophthora infestans and Fusarium solani. European Journal of Plant Pathology 123, 47-56

Onkendi, E. M. and Moleleki, L. N. 2013a. Detection of Meloidogyne enterolobii in potatoes in South Africa and phylogenetic analysis based on intergenic region and mitochondrial DNA sequences. European Journal of Plant Pathology 136, 1-5

Onkendi, E. M. and Moleleki, L. N. 2013b. Distribution and genetic diversity of root-knot nematodes (Meloidogyne spp.) in potatoes from South Africa. Plant Pathology 62, 11841192

Onkendi E. M., Kariuki G. M., Marais M. and Moleleki L. N. 2014. The threat of root-knot nematodes (Meloidogyne spp.) in Africa: a review. Plant Pathology 63, 727 -737 
Porat R., Vinokur V., Weiss B., Cohen L., Daus A., Goldschimidt E.E. and Droby S. (2003) Induction of resistance to Penicillium digitatum in grapefruit by $\beta$-aminobutyric acid. European Journal of Plant Pathology 109, 901-907

Siddiqui, Z.A., Nesha, R., Singh, N. and Alam, S. 2010. Interactions of plant-parasitic nematodes and plantpathogenic bacteria. In: Bacteria in Agrobiology: Plant Probiotics ed. Maheshwari, D.K. pp 251-257. Berlin Heidelberg: Springer-Verlag.

Taylor, A. L., and Sasser, J. N. 1978. Biology, identification and control of root-knot nematodes (Meloidogyne species). N.C. State University Graphics: Raleigh, N.C.

Udo, I. A., Ugwuoke, K. I. and Ukeh, D. A. 2003. Antagonistic effect of Meloidogyne incognita and $M$. javanica on pepper veinal mottle virus (PVMV) (Genus: Potyvirus) infecting Nigerian pepper (Capsicum sp.) lines. Agricultural Journal 3(1), 31-35

Vallad, G. E. and Goodman, R. M. 2004. Systemic acquired resistance and induced systemic resistance in conventional agriculture. Crop Science 44, 1920-1934

Vieira dos Santos, M. C., Curtis R. H. C and Abrantes, I. 2013. Effect of plant elicitors on the reproduction of the root knot nematode Meloidgyne chitwoodi on susceptible hosts. European Journal of Plant Pathology 136, 193-202

Walker, W. R., Kirkpatrick, T. L. and Rothrock, C. S. 1998. Interaction between Meloidogyne incognita and Thelaviopsis basicola on cotton (Gossypium hirsutum). Journal of Nematology, 30(4), 415-422 